\title{
Seasonal Arctic sea-ice simulations with a prognostic ice-ocean model
}

\author{
Peter H. Ranelli and W.D. Hibler, iil \\ Thayer School of Engineering, Dartmouth College, Hanover, NH 03755, U.S.A.
}

\begin{abstract}
A prognostic ice-ocean model of the Arctic, Greenland and Norwegian seas with daily wind and atmospheric forcing is integrated for 30 years to quasi-equilibrium. Three simulations are carried out to investigate the role played by ice deformation and transport in baroclinic adjustment of the Arctic Ocean: a standard run with precipitation and ice transport, a simulation without precipitation and a "thermodynamics only" simulation without ice transport but including precipitation. A diagnostic model is integrated for five years to serve as a comparative control run. Comparison of the vertically integrated stream-function of each of the model runs indicates that the vertical density stratification needed to maintain the circulation of the Arctic Ocean is reduced excessively when precipitation is neglected and artificially enhanced if ice transport out of the basin is ignored. This effect is even more noticeable in the surface currents and is also apparent in a comparison of simulated and observed drifting-buoy tracks. An analysis of the salt budget of the Arctic Ocean indicates that the three main components, salt transport by the ocean, salt flux from the annual cycle of ice, and a fresh-water flux from precipitation and river runoff are approximately of the same magnitude. The main circulation deficiency identified in the simulations is an inadequate flow of Atlantic water into the Arctic Basin through the Fram Strait.
\end{abstract}

\section{INTRODUCTION}

Earlier studies with coupled ice-ocean models have been made by Hibler and Bryan (1987) and Semtner (1987). Hibler and Bryan carried out a diagnostic simulation (in which the temperature and salinity were constrained by climatological values) of the Arctic ice-ocean system by integrating a coupled ice-ocean model for five years. In this simulation, the mean baroclinic circulation deviated little from the initial fields, although seasonal and local variations were simulated by virtue of allowing a weak (three year damping time) rather than rigid relaxation to observed data. As a consequence, the long-term salt and heat budgets of the coupled ice-ocean model could not be determined. Whereas this diagnostic model yielded good results for the location of the ice margin, a global budget analysis indicated that the net northward heat transport through the Faroe-Shetland passage was not adequate to balance the heat loss to the atmosphere sustained by the ocean in the fifth year. Moreover, a 20 year simulation using a prognostic model (in which the temperature and salinity are allowed to evolve freely) showed a degradation of the baroclinic velocity fields in the Arctic Basin. For a better understanding of the evolution of the internal temperature, salinity and momentum structure of the ocean, and the role of the Arctic ice-ocean system in the global climate system, a fully prognostic ice-ocean model, in which the temperature and salinity of the ocean are allowed to evolve freely, is clearly required.

A prognostic ice-ocean study with different boundary conditions and external forcing was carried out by Semtner (1987). In Semtner's study, mean monthly winds were used to force an ice-ocean model in which a cavitating-fluid ice rheology (for a comparison of different sea-ice rheologies see Ip and others (1991)) and fixed southern transports through the Denmark Strait and the Iceland-Faroe-Shetland passages were employed. In Semtner's study, much of the emphasis was on the East Greenland ice edge and a detailed analysis of the salt and heat budgets for the Arctic Basin was not carried out. Also, because of the use of mean monthly forcing and a simplified sea-ice model, many details of the ice-stress transfer into the ocean and the effect of ice deformation on salt budgets and ice transport could not be examined. Moreover, this type of simulation allowed no direct comparison to observed buoy drift.

To address some of these issues, and to begin to understand the basic physics of the baroclinic adjustment of the Arctic Ocean, we have carried out a series of 30 year prognostic ice-ocean simulations using daily wind and atmospheric forcing fields from 1981. (This particular year was selected because of the similarity of its winds to climatological winds.) In these simulations, we have focused on the role of the salt budget on the baroclinic 
adjustment of the Arctic Ocean and the critical role that ice deformation and transport play in the spin-up or spindown (i.e. evolution) of the surface currents. In particular, to help clarify this issue, we have carried out three basic simulations: a "standard" run with precipitation and ice transport, a "high salt" simulation without precipitation and, finally, a "thermodynamics only" simulation without ice transport but including precipitation. As will be shown, comparison of these various prognostic simulations with one another, and with a control "diagnostic" simulation, is helpful in identifying the role of the various salt-budget processes on the baroclinic adjustment of the Arctic Ocean.

\section{MODEL DESCRIPTION}

A large-scale (160 km horizontal resolution, 14 vertical levels) numerical ice-ocean model of the Arctic Ocean was created by Hibler and Bryan (1987) by coupling the dynamic-thermodynamic ice model of Hibler (1979) to the multi-level baroclinic ocean model of Bryan (1969). In the diagnostic model, except in the upper layer $(30 \mathrm{~m})$ of the ocean, observed temperature and salinity data are used to force the ocean rather than allowing a full simulation of the temperature and salinity. The upper layer surface salt, heat and momentum fluxes are dictated by the ice model. The diagnostic model has been used to study seasonal (Hibler and Bryan, 1987) and interannual variations (Hibler and Ranelli, 1990) in the sea-ice fields.

By removing the diagnostic forcing, an ice-ocean model in which the temperature and salinity of the ocean are allowed to evolve freely is created. In this prognostic model, the forcing of temperature and salinity to observed data has been removed except at the open lateral boundaries in the Bering Strait and the North Atlantic just south of Iceland. At these boundaries (Fig. 1), the temperature and salinity are forced to observed values on a $30 \mathrm{~d}$ time scale in order to simulate realistic boundary fluxes. Since the model boundary south of Iceland is removed from the main area of interest and analysis, and the flow through the Bering Strait is a small portion of the total model flow into the Arctic Ocean, these lateral constraints were not felt to have a large impact on the ocean simulation. This prognostic model more fully incorporates the effects of sea ice on ocean circulation.

In order to test the effect of precipitation on the salt budget, a crude snowfall parameterization was added to the ice-ocean model. The model was modified to include a precipitation rate of $20 \mathrm{~cm} \mathrm{yr}^{-1}$ of water directly into the ocean. This is somewhat more than the $13.4 \mathrm{~cm} \mathrm{yr}^{-1}$ of water used by Parkinson and Washington (1979). A correct coupling would allow precipitation to fall on either the ice or ocean, the portion on the ice drifting according to ice dynamics and then melting into the ocean at some later time. However, considering the limitations of the ocean circulation model, the simplified method used here was felt to be adequate for a preliminary investigation of the effects of precipitation.

\section{Model runs}

To drive the ice-ocean model, atmospheric forcing fields of geostrophic winds, surface air temperature and relative

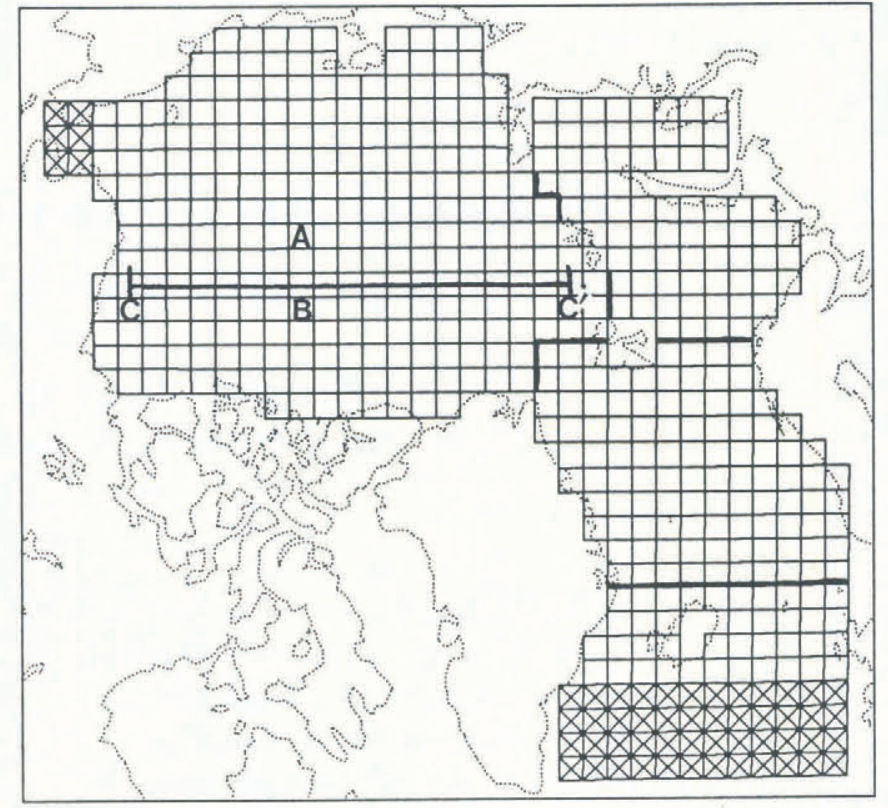

Fig. 1. Grid configuration used for the ice-ocean model. The cross-hatched grid cells are boundary cells with a $30 \mathrm{~d}$ relaxation. The heavy black lines divide the grid into the Arctic, Greenland and Barents seas for analysis purposes. Grid cell $A$ indicates the location of the stream-function timeseries in Figure 2 and grid cell $B$ indicates the location of the salinity profiles in Figure 7. Line $C-C$ is the transect line used in Figure 6.

humidity were interpolated from $5^{\circ}$ by $5^{\circ}$ latitudelongitude fields for 1981 provided by Walsh (personal communication). The winds were computed geostrophically from National Center for Atmospheric Research (NCAR) daily surface pressure analyses merged with objective interpolation of Arctic data-buoy pressures. The air temperatures were from monthly mean temperature fields obtained from National Aeronautics and Space Administration (NASA) analyses. The shortwave and longwave radiation were computed using the formulations of Parkinson and Washington (1979).

Using these atmospheric forcing fields, three prognostic 31 year ice-ocean simulations were carried out. In addition, a 5 year diagnostic simulation was performed as a comparative control run. It should be emphasized that the "observed" temperature and salinity used in the diagnostic model represent a very crude long-term averaged view of the hydrography of the Arctic Ocean. Nevertheless, we would ideally like the prognostic simulations to evolve to a state of density stratification and surface currents that are qualitatively represented by these "observed" data. Daily time-varying winds and atmospheric forcing were used for all simulations.

For the prognostic model simulations, the standard simulation (designated mnemonically as "RAIN") was initialized with the same observed temperature and salinity as was used in the "diagnostic" run. Also, precipitation was included as discussed above. However, no relaxation to observed temperature and salinity was used (except lateral "flux" boundary regions). To analyze the effect of surface salt fluxes on the Arctic Ocean baroclinic adjustment, two other simulations were 


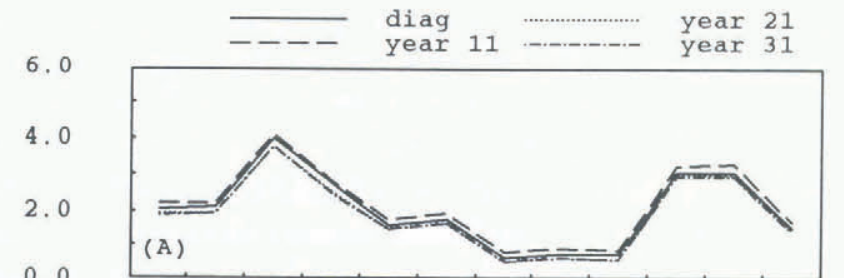

0.0

5. 0

3.0

1. 0

$-1.0$

6. 0

4. 0

2. 0

0.0
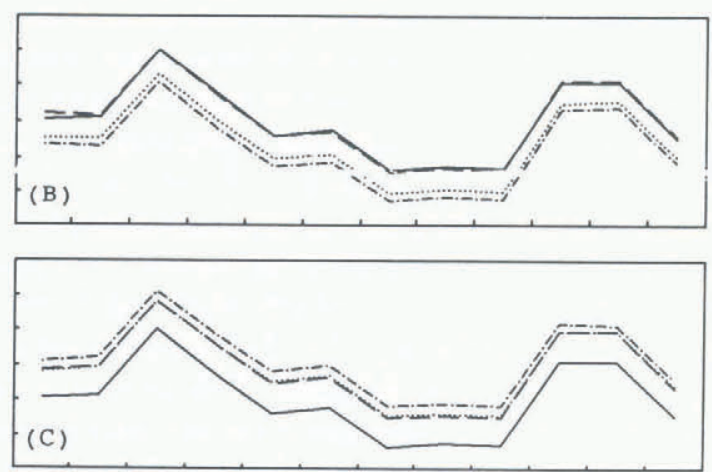

$\begin{array}{lllllllllllll}0 & 1 & 2 & 3 & 4 & 5 & 6 & 7 & 8 & 9 & 10 & 11 & 12\end{array}$

\section{MONTH}

Fig. 2. Time series of the mean monthly vertically integrated stream-function for years 11, 21 and 31 of the (a) RAIN model run (b) NORAIN model run and (c) THERMO model run.
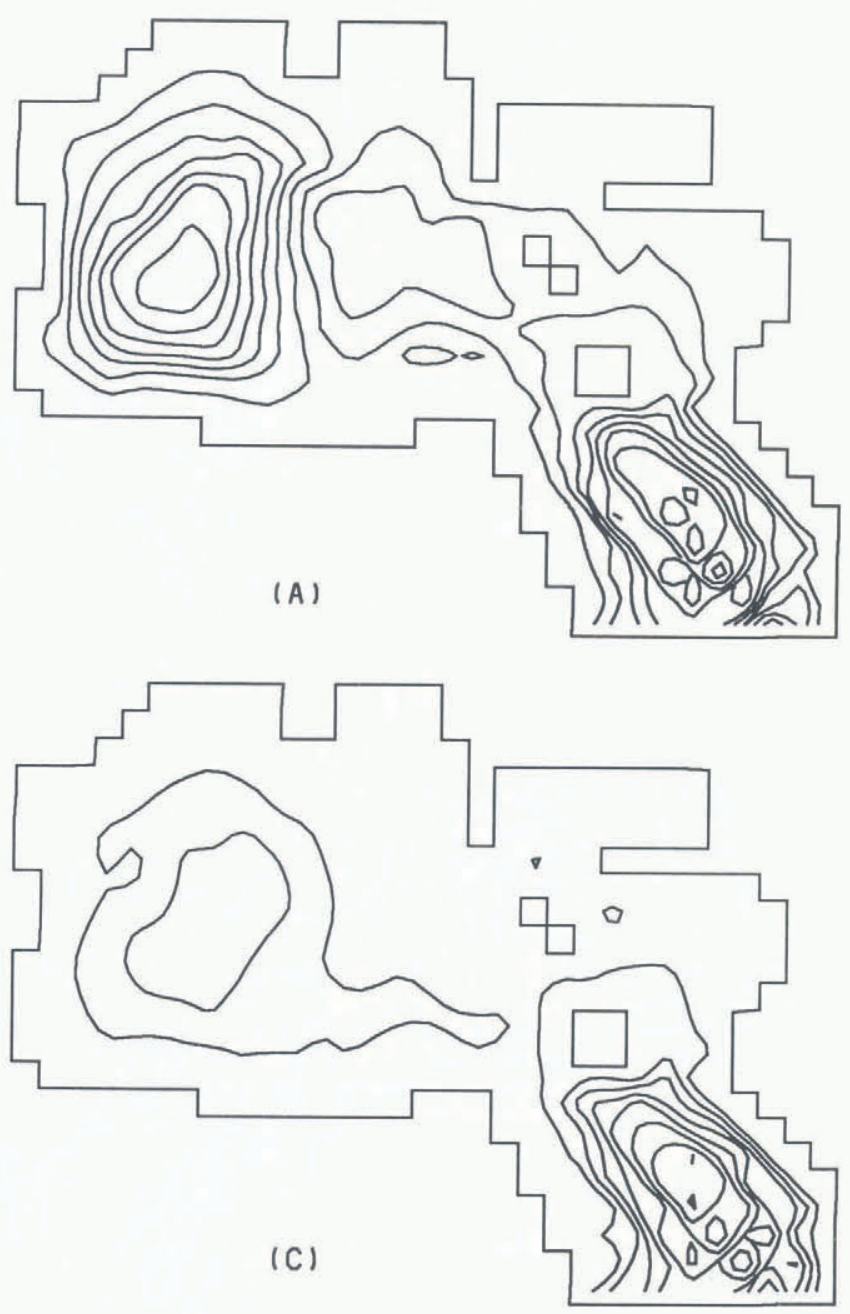

performed. One was with no precipitation (designated "NORAIN") and one without ice transport or ice dynamics (designated "THERMO") in which a "thermodynamics only" ice model was employed. In the THERMO simulation, precipitation was included and daily stress into the ocean was taken from the standard RAIN simulation. All prognostic models were integrated at $1 \mathrm{~d}$ time-steps for 31 years.

\section{SIMULATION RESULTS}

Each model run is integrated for 30 years using $1 \mathrm{~d}$ timesteps and forcing fields, as described above, until quasiequilibrium is reached. The results for years 11,21 and 31 are analyzed, with particular attention given to the ocean circulation in the Arctic Basin and the individual terms in the salt budget. The diagnostic simulation reaches quasiequilibrium after four years (Hibler and Bryan, 1987) and the fifth year is used for comparisons.

\section{Ocean and ice circulation}

Time series of the vertically integrated stream-function for the three prognostic simulations, and the fifth year of an integration of the diagnostic model, are shown in Figure 2. This is the mean monthly stream-function for a point near the center of the Beaufort Gyre, as indicated on Figure 1.
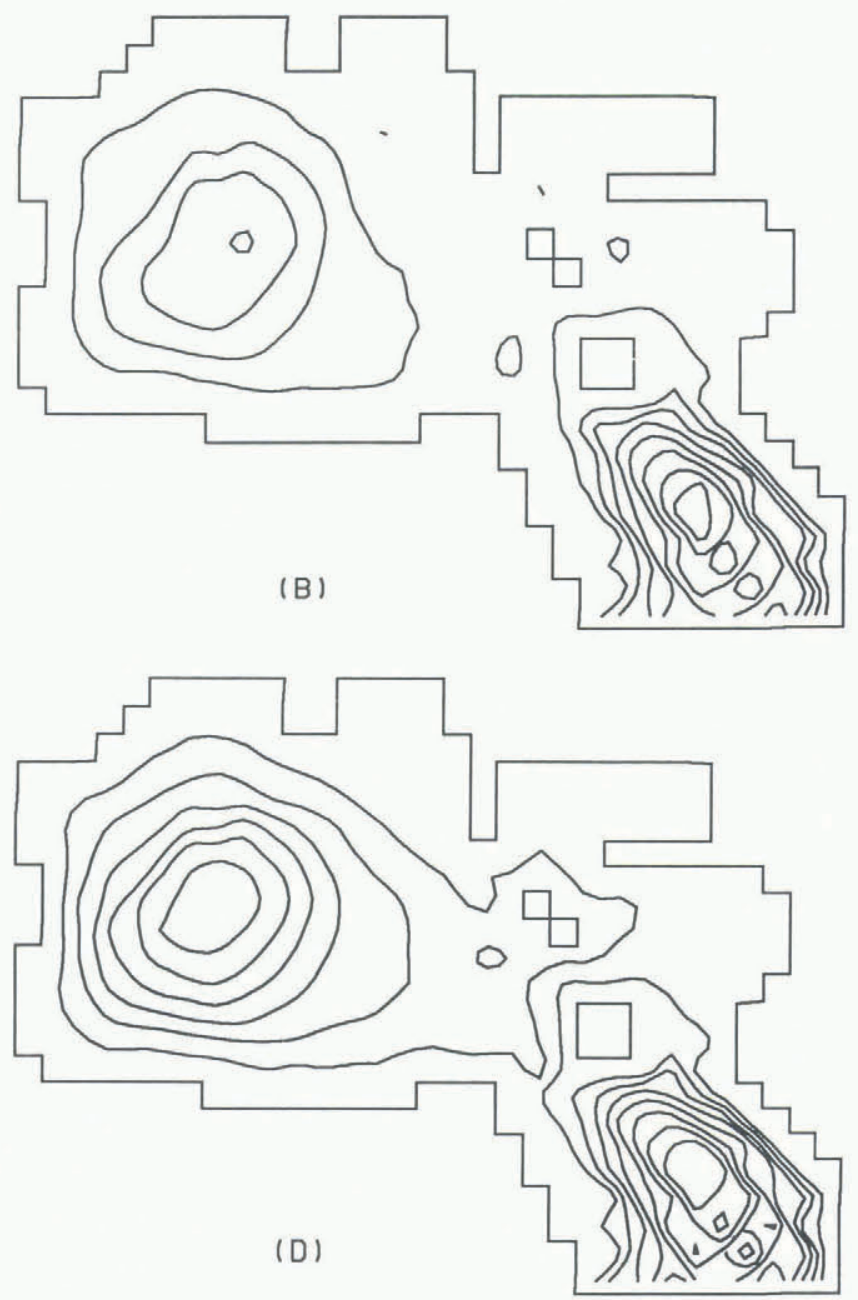

Fig. 3. Contour plots of the annual average stream-function for (a) diagnostic model-year 5, (b) RAIN-year 31, (c) NORAIN-year 31, (d) THERMO-year 31. Contour interval is $0.5 \mathrm{~Sv}$. The circulation is cyclonic in the Greenland-Iceland-Norwegian sea and anti-cyclonic in the Canadian Basin. 
All model runs show the same variability within a given year in response to the varying winds. The strongest circulation is in March and the weakest in the summer months. However, the strength of the stream-function in NORAIN decreases during the entire model run and reverses during the summer in years 21 and 31 . The decrease in RAIN is significantly less, and there is very little change between years 21 and 31 . The streamfunction for RAIN and year 11 of NORAIN compares favorably to the results of the diagnostic model. However, the results of years 21 and 31 of NORAIN are significantly less. These results can be contrasted with the THERMO simulation, where the lack of salt input to the ocean, due to no ice transport out of the Arctic Basin, causes greater stratification. This greater stratification, when combined with Ekman pumping, causes greater lateral variations in density and, hence, an increased bottom torque term in the vertically integrated vorticity equation. On the other hand, in the NORAIN simulation, the stratification is gradually weakened, thus causing a decrease in the bottom torque term and an overall decay of the robustness of the ocean simulation.

A comparison of the annual average stream-function throughout the entire model area (Fig. 3) generally supports the above conclusions. It shows a much larger decrease in the circulation in the Arctic Ocean, particularly of the Beaufort Gyre, in the case of NORAIN as compared to RAIN, as well as an increase in the circulation in the case of THERMO. None of the prognostic models yields the counter-clockwise gyre in the Eurasian Basin that is weakly apparent in the diagnostic model. Whereas this may be dependent on the salt budget, more localized simulations suggest it to be at least partially due to low horizontal resolution, with the concomitant poor resolution of topography and excessively high lateral eddy viscosity. These two factors also undoubtedly affect the integrated transport through Fram Strait which also does not appear very realistic.

The circulation in the Greenland and Norwegian seas is relatively unchanged by the different treatments of precipitation and ice dynamics. This, in turn, suggests that this region is more dominated by the oceanic transport at the southern boundary and the overall barotropic flow in this region. Analysis of the global salt budgets, presented later, generally supports this view. However, there are some interesting differences in this region, with NORAIN having a counter-clockwise circulation into the Barents Sea and around Svalbard. The THERMO case, on the
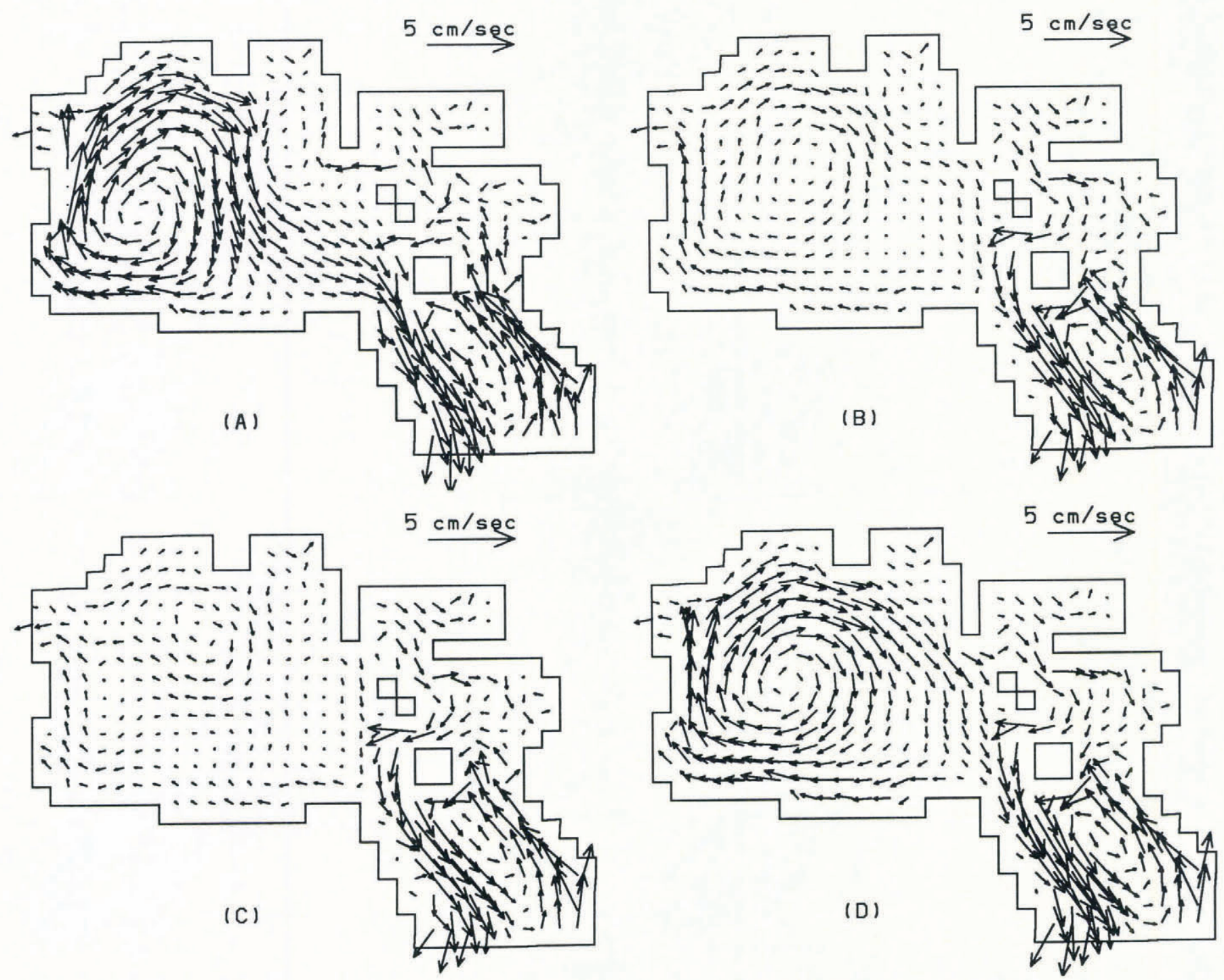

Fig. 4. The annual average surface ocean velocities for (a) diagnostic model-year 5, (b) RAIN-year 31, (c) NORAIN-year 31, (d) THERMO-year 31. Vector lengths are scaled to $5 \mathrm{~cm} \mathrm{~s}^{-1}$. 
other hand, has the clockwise circulation observed in the Arctic Basin expanding into the Barents Sea and then returning around Franz Josef Land.

Whereas there are differences in the integrated flow between the two models, it is the surface currents (Fig. 4) where the differences between the models become most noticeable. As can be seen from Figure 4, the surface manifestation of the Beaufort Gyre practically disappears in NORAIN and what gyre remains is shifted to the west, very close to Siberia. THERMO, on the other hand, has a substantially enhanced surface circulation with a somewhat stronger gyre than in the diagnostic case. While still retaining the Beaufort Gyre, RAIN still has some weakening of the gyre, compared to the diagnostic control run, and a shifting of the gyre closer to the Siberian shelf. It is notable that, except near the coast and in contrast to the integrated flow, the surface currents change very little between winter and summer and, hence, are much more geostrophic in character. As in the streamfunction, there are few changes in the East Greenland Current, although it can be seen that the lack of ice transport in THERMO causes slightly higher currents near the coast of East Greenland and, hence, shifts the region of lateral current shear closer to the coast.

The change of the currents and their effects on ice motion can be examined by comparing observed buoy drift to simulated buoy drift (Fig. 5 and Table 1). In these comparisons, the location of the observed buoy was first identified and the corresponding buoy drifts were calculated for a month from model runs and observed data. The resulting monthly drifts are then compared, to determine the distance between the buoy locations at the end of the month (error radius) and the error in the drift angle. To avoid extreme values, drift-angle errors were not computed when the observed buoy drift was more than one standard deviation below the mean. The six buoy tracks shown began in June 1981 and the comparison runs from June to December 1981. Buoy tracks are calculated for year 31 of the prognostic models, for year 5 of the diagnostic model and for year 4 of an ice-only model. The ice-only model is included to illustrate the effect of ocean currents.

There are several general points to be deduced from

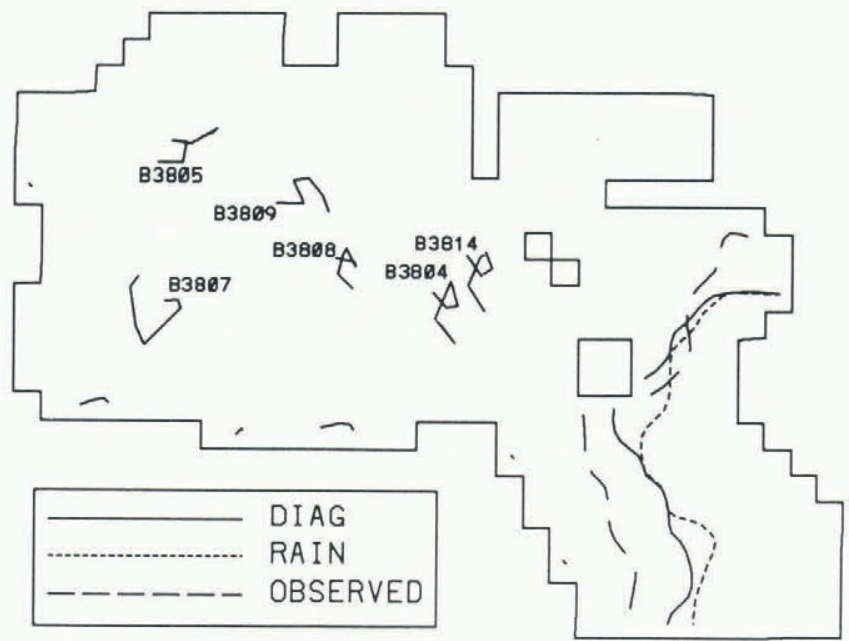

Fig. 5. Location of observed buoy-tracks used for comparison to simulated buoy tracks, and the observed and simulated ice edge for March. The ice edge is taken as 0.2 compactness. The model results are for year 31 .

Table 1. First, by year 31 , NORAIN provides a poorer simulation of the observed buoy track than does RAIN. Next, inclusion of ocean currents provides a slightly better correlation to the observed track in the diagnostic and RAIN models, although the simulations appear more similar to each other than to the observed tracks. Moreover, RAIN shows some degradation of the surface currents (as shown by their effects on ice drift) as compared to the diagnostic model. It should be emphasized that the reduced barotropic current in certain locations, caused by the high eddy viscosity necessitated by the crude resolution, undoubtedly affects these results. Finally, the model tracks have a slight bias to the left of the observed track, although there is a large spread of values to both the left and right of the observed track. This is possibly caused by the simple boundary layer treatment used in the model.

The magnitude of the effect of the ocean surface currents and sea-surface tilt on simulated buoy drift is seen in Table 2. The average vector difference between the drift

Table 1. Comparison of observed and simulated buoy tracks, based on average monthly data. The average error is the distance between the observed and simulated buoy location at the end of each month. The drift-angle error (in degrees) is the difference in the direction of the observed buoy drift and the model buoy drift. In the case of the drift-angle errors, the $80 \%$ confidence interval (CI) is given rather than the standard deviation. The standard deviation can be determined by multiplying the confidence interval by a factor of 4.62. Positive deviation angles indicate that simulated movement is to the left of the observed buoy movement

$\begin{array}{ccccc}\begin{array}{c}\text { Model } \\ \text { type }\end{array} & \begin{array}{c}\text { Monthly drift } \\ \text { magnitude }(\mathrm{km})\end{array} & \begin{array}{c}\text { Average error } \\ \text { radius }(\mathrm{km})\end{array} & \begin{array}{c}\text { Drift-angle } \\ \text { error } / \mathrm{CI}\end{array} & \begin{array}{c}\text { Correlation } \\ \text { coefficient }\end{array}\end{array}$

$\begin{array}{ll}\text { Observed } & 125.90 \pm 59.26 \\ \text { Diag } & 138.19 \pm 71.35 \\ \text { RAIN } & 134.53 \pm 70.38 \\ \text { NORAIN } & 134.78 \pm 69.48 \\ \text { Ice-only } & 127.35 \pm 70.29\end{array}$

$76.64 \pm 35.98$

$80.62 \pm 38.60$

$77.64 \pm 34.30$

$9.88 / 6.32$
$7.94 / 7.99$
$6.50 / 9.09$
$0.07 / 6.92$


Table 2. Effect of the ocean on the average monthly buoy drift as a change from the buoy drift simulated by the ice-only model. Direction is relative to the direction of the ice-only drift, with positive angles to the left. Per cent change is relative to the average monthly drift for the ice-only model $(127.35 \mathrm{~km})$

\begin{tabular}{lcrr}
\hline $\begin{array}{c}\text { Model } \\
\text { type }\end{array}$ & $\begin{array}{c}\text { Average } \\
\text { difference }(\mathrm{km})\end{array}$ & $\begin{array}{c}\text { Relative } \\
\text { direction }\end{array}$ & $\begin{array}{c}\text { Per cent } \\
\text { change }\end{array}$ \\
\hline & & & \\
Diag & 26.58 & -16.84 & 20.87 \\
RAIN & 14.93 & 10.65 & 11.73 \\
NORAIN & 15.32 & -5.44 & 12.03 \\
\hline
\end{tabular}

as simulated by the three ice-ocean models and the drift as simulated by the ice-only model are shown. The distance is the vector magnitude between the two final locations and the direction of the vector is relative to the direction of the ice drift. For the monthly periods examined here, the ocean has a significant effect on the ice motion, accounting for up to $20 \%$ of the simulated buoy drift. Over longer periods, the ocean contribution is expected to be higher.

The indirect effect of ocean currents vis-á-vis lateral heat transport on the ice edge is also seen in Figure 5. There is little difference among the ice edges as modeled by the three simulations (for clarity, only RAIN is shown). The differences between RAIN and the diagnostic model are also small except for a noticeable difference in the Greenland-Iceland-Norwegian sea. Both the "Odden"like feature and the ice edge close to Svalbard are more advanced in RAIN. In this model, the outflow from the Barents Sea and the recirculation from the East Greenland Current is somewhat stronger, demonstrating the importance of ocean currents in determining the location of the ice edge. Whereas both models have realistic results in the Barents Sea, they have a much greater areal extent than the observed ice edge in the Greenland-Iceland-Norwegian sea. While this deficiency is partially due to inadequate horizontal resolution (Ries and Hibler, 1991), a more major problem is the lack of turbulent boundary layer parameterization in the ice-ocean model.

\section{Arctic Basin salinity structure}

The decrease in the circulation in NORAIN is due to a decrease in the vertical stratification of the top layers of the ocean resulting from an increase in the salinity.This is illustrated in Figure 6, which compares a cross-section of salinity in the upper $300 \mathrm{~m}$ of the Arctic Ocean. At temperatures close to freezing, changes in the density are dominated by changes in the salinity. This means that greater salinity produces a much deeper isopycnic layer and a weaker pycnocline. As can be seen from the salinity sections in Figure 6, NORAIN has almost totally lost the fresh-water lens in the center of the Beaufort Gyre. While weakening somewhat, it is still maintained in RAIN with a little weakening of the vertical density. Whereas its shape is about the same in THERMO and RAIN, the vertical variation of the salinity is much greater in THERMO. This similar structure of RAIN and THERMO suggests
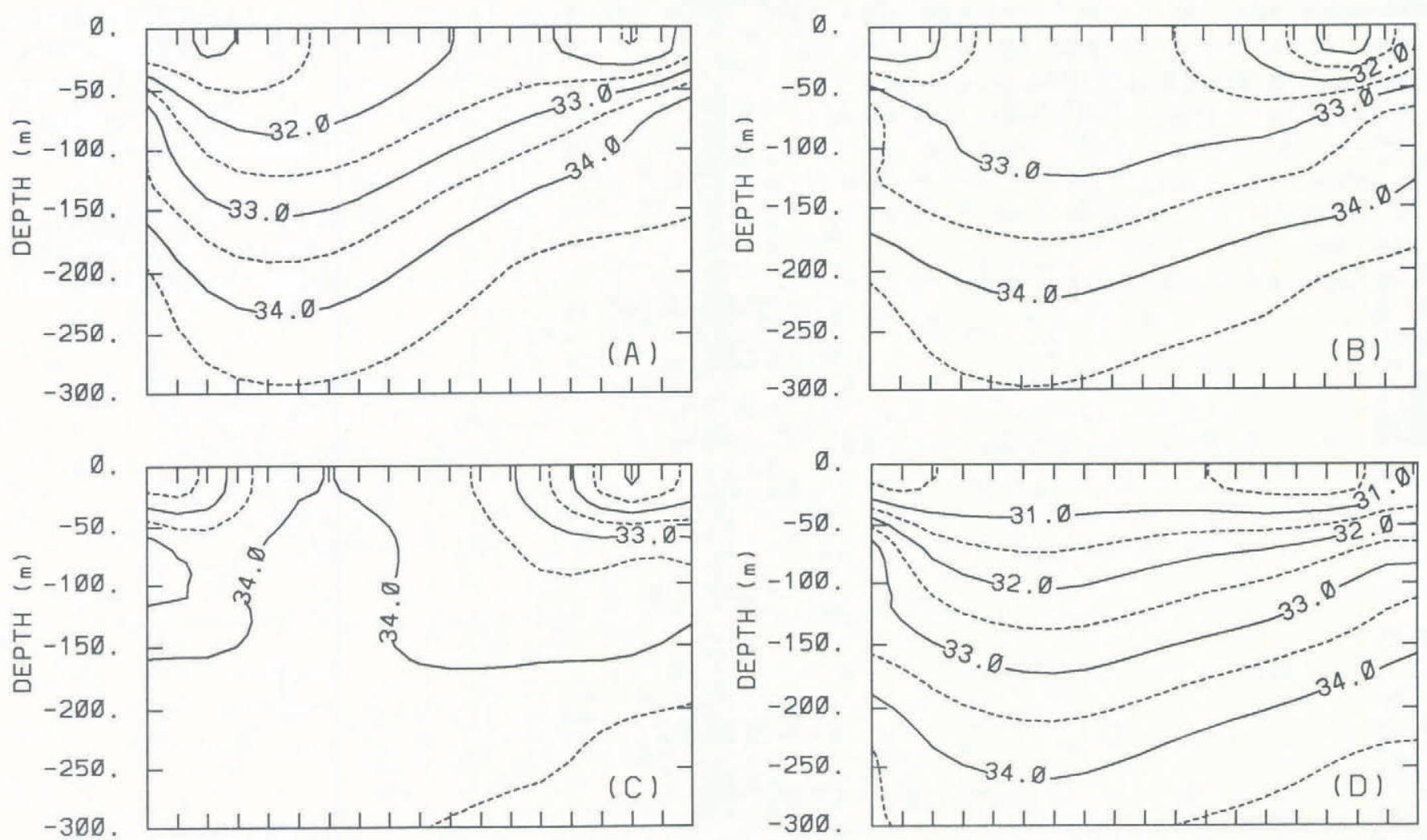

Fig. 6. Vertical profiles of the annual average salinity along transect shown in Figure 1 for (a) diagnostic-year 5, (b) RAIN-year 31, (c) NORAIN-year 31 and (d) THERMO-year 31. Contour interval is 0.5 ppt. Tick marks are one grid cell apart $(160 \mathrm{~km})$. 

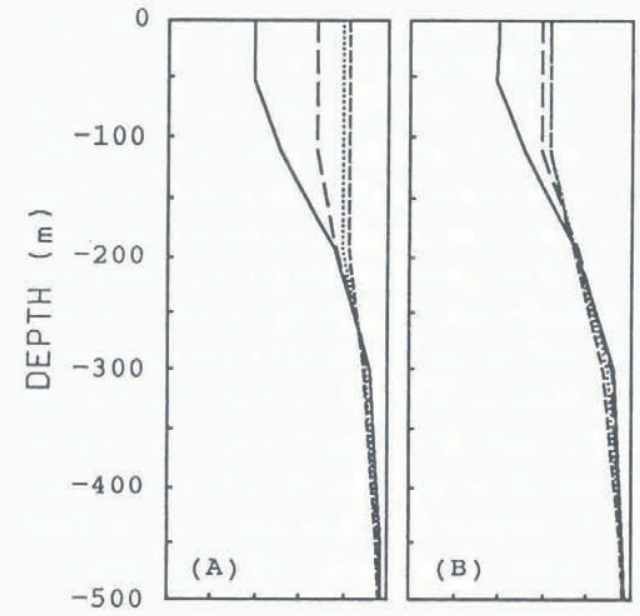

31

$33 \quad 35$

31

33
35

SALINITY

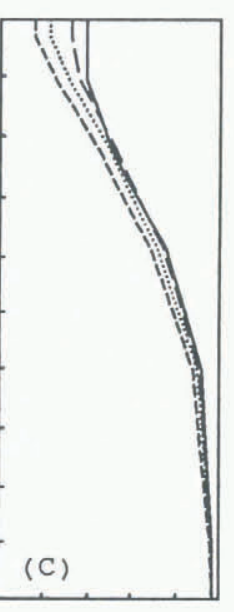

DIAG-yr5

Year 11

Year 21

Year 31

Fig. 7. Salinity profiles of the top $500 \mathrm{~m}$ of the ocean for day 90 of years 11, 21 and 31 of (a) RAIN, (b) NORAIN and (c) THERMO. The profile for year 5 of the diagnostic model run is shown for comparison.

that as long as the stratification is present, the Ekman pumping due to the wind is the main cause of the baroclinic adjustment. However, the fact that the surface currents change relatively little in summer indicates that the time-scale for the bending of the density fields is at least on the order of several months.

The slow evolution of the vertical density structure is illustrated in Figure 7. In NORAIN, most of the change from the diagnostic profile occurs between years 11 and 21 as, by year 21, the isopycnic surface layer has increased to about $200 \mathrm{~m}$. In THERMO, the shape of the vertical stratification continues to steepen in a smooth manner. In RAIN, the stratification weakens slightly between years 11 and 21 and then becomes relatively stable. The temperature profiles (not shown) reflect the changing density conditions, with the depth of the isothermal surface layer (at $-1.96^{\circ} \mathrm{C}$ ) corresponding to the depth of the isohaline (and isopycnic) layer.

\section{Arctic Basin salt budget}

Whereas spatial variations can occur, the overall vertical stratification must be linked to the change in the total salt content of a region over a period of time, due to the processes of ocean transport, ice export, fresh-water flux and diffusion. Here, we define ocean transport as the amount of salt that crosses the boundaries of a given region due to ocean circulation. Ice exported from a region leaves behind the salt rejected during freezing. The fresh-water flux is a constant value over the period of one year and is due to river runoff and precipitation. The fluxes of salt due to fresh-water and ice export are set at $30 \mathrm{ppt}$ and mixed into the top layer $(30 \mathrm{~m})$ of the ocean model either at designated grid cells on the model periphery for river runoff or everywhere at the surface for precipitation. It should be noted that the budget is not strictly balanced since the ice model is in rectangular coordinates and the ocean model is in spherical coordinates. This results in a creation of salt in the conversion of ice formed in the ice model to a salt flux in the ocean model, but this is considered a small effect and mainly impacts the Greenland and Norwegian seas (see Hibler and Bryan, 1987, Appendix A, for additional details).

To analyze the global salt budgets, the model grid is divided into three geographical regions, approximating the Arctic Ocean, the Greenland-Norwegian sea and the Barents Sea (Fig. 1). Only the salt budget of the Arctic Ocean is analyzed here to determine the effects of precipitation and ice transport. The specified fresh-water flux in the Arctic Ocean (in terms of a negative salt flux) is $1.315 \times 10^{6} \mathrm{~kg} \mathrm{~s}^{-1}$ for precipitation and $0.633 \times 10^{6} \mathrm{~kg} \mathrm{~s}^{-1}$ for river runoff.

The salt transport through the three main passages into the Arctic Basin is shown in Table 3. The most sriking features are the large outflows through Fram Strait and the inflow through the passage between Svalbard and Franz Josef Land (FJ1). Whereas observations indicate that the East Greenland Current outflow through Fram Strait is expected to be partially balanced by the West Spitsbergen Current (Aagard and Carmack, 1989), the simulations have a strong outflow corresponding to the East Greenland Current only. The water normally part of the West Spitsbergen Current is diverted to the east of Svalbard and enters the Arctic Basin predominantly through FJ1. The anomalous flow through Fram Strait is most likely due to the low horizontal resolution and the poor resolution of topography. The net transport through the three passages is small when compared to the individual terms, but is an important term in the overall salt budget of the Arctic Ocean. The magnitudes of the salt transports are largest in NORAIN and smallest in THERMO. This is consistent with both the differences in the transport (Fig. 3) and the changes in the salt content.

The long-term evolution of the total salt content of the Arctic Ocean for each model run is shown in Figure 8. In addition, the contributions of ocean transport, ice export and fresh-water flux in year 31 of the prognostic simulations and year 5 of the diagnostic simulation are

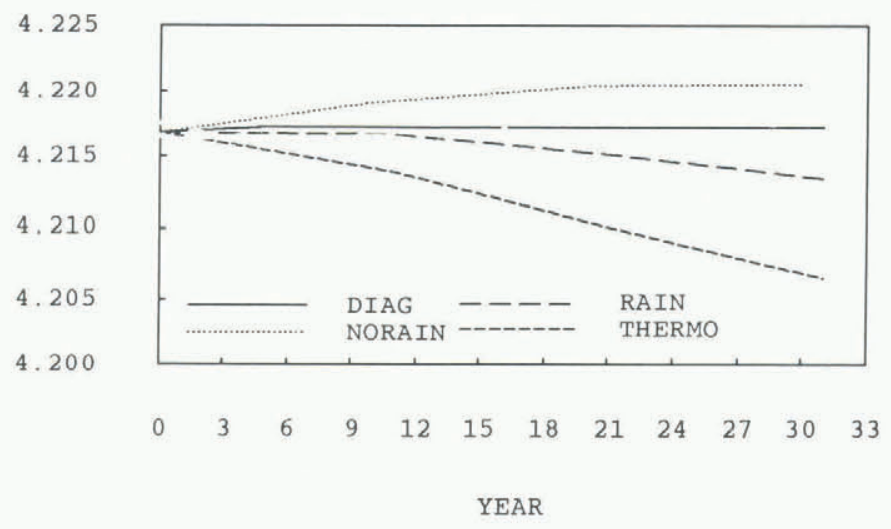

Fig. 8. The total salt content in the Arctic Basin during the model runs. Units are $10^{16} \mathrm{~kg}$. The salt content for year 5 of the diagnostic simulation has been extended to year 31 for comparison purposes. 


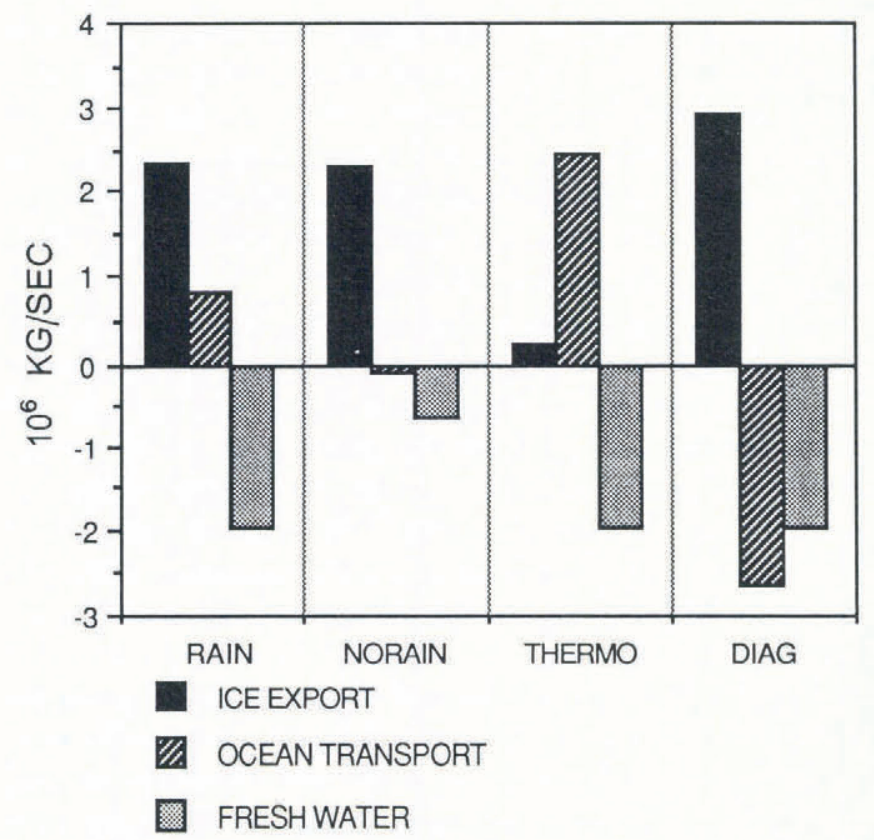

Fig. 9. The individual components of the salt budget at year 31 of the four model runs. Units are in $10^{6} \mathrm{~kg} \mathrm{~s}^{-1}$.

shown in Figure 9. Since the relaxation to observed temperature and salinity in the diagnostic model is a source of salt, the three budget components shown do not balance in this model run. The effect of precipitation on the total salt content is made clear by a comparison of the results for NORAIN and RAIN, whereas the results for THERMO demonstrate the need for ice dynamics to maintain the correct salt content in the Arctic Basin. The slightly smaller salt content in RAIN, as compared to the diagnostic simulation, indicates that the $20 \mathrm{~cm} \mathrm{yr}^{-1}$ precipitation rate used in these models may be too large. The salt fluxes (Fig. 9) due to ice export are almost equal in RAIN and NORAIN and are close to the value of the diagnostic simulation. This large influx of salt is not compensated completely by oceanic transport and freshwater flux in NORAIN. The outflow of salt in NORAIN reflects the much greater salinity in the Arctic Basin and begins to compensate for the increase in the greater total salt content.

Table 3. Oceanic salt transport through three passages into the Arctic Basin. FRAM is Fram Strait, FJ1 is the passage between Svalbard and Franz Josef Land and FJ2 is the passage between Franz Josef Land and Severnaya Zemlya. Units of $10^{6} \mathrm{~kg} \mathrm{~s}^{-1}$. Positive transports indicate salt entering the Arctic Basin

\begin{tabular}{llll}
$\begin{array}{l}\text { Model } \\
\text { type }\end{array}$ & FRAM & FJI & FJ2 \\
\hline & & & \\
Diag & -36.66 & 23.37 & 16.07 \\
RAIN & -13.24 & 21.25 & -7.12 \\
NORAIN & -22.38 & 29.61 & -6.54 \\
THERMO & -7.60 & 20.98 & 10.85
\end{tabular}

A comparison of the salt content for RAIN and THERMO shows the importance of ice transport on the salt budget. In THERMO, there is no ice export since the ice model is used without dynamics. Hence, when the model reaches thermodynamic equilibrium, there is no net growth over an annual cycle and the contribution of salt flux to the budget will be zero. At year 31, this condition has almost been satisfied and the salt flux is close to zero (Fig. 8). The salt content in THERMO decreases at a much greater rate than in RAIN, since the fresh-water flux is not balanced completely by the net salt transport in THERMO. Whereas all the models will ultimately reach a steady state as the oceanic transport adjusts, the final state will clearly have significantly different streamfunctions.

\section{CONGLUSIONS}

A coupled ice-ocean model has been used to make prognostic simulations to examine the effect of different forcing mechanisms on the circulation and salt budget of the Arctic Ocean. While the somewhat crude resolution and excessive lateral damping produce anomalous results in certain locations, such as poor inflow through Fram Strait, the results were felt to be adequate for an estimation of the major salt budget processes affecting the baroclinic adjustment of the Arctic Ocean. An understanding of these processes is necessary before incorporating them into a higher-resolution model.

Overall, the main result of this study was the indirect effect of the salt budget on the Arctic Basin circulation by means of modifying the Arctic Basin stratification. In particular, without precipitation, the Arctic Ocean stream-function reduced greatly and the surface current structure lost its classical gyre motion. With no ice export, on the other hand, the stream-function is enhanced and the circulation and the surface currents increase. Due to much smaller loss of circulation in the central Arctic Ocean, the prognostic ice-ocean model with precipitation was found to provide a better simulation of ocean circulation as evidenced by an examination of buoy drift tracks. The baroclinic adjustment process was found to occur on a time scale of at least several months and appears to be due mainly to Ekman pumping.

In agreement with observational estimates, the salt budget of the Arctic Basin was found to have three important components: salt flux due to ice export, salt transport by ocean circulation and fresh-water flux from precipitation and river runoff. Of these three, the ice export is the largest component. The large salt export through Fram Strait was abnormal and traced to a much smaller inflow from the Greenland Sea to the Arctic Ocean. The flow associated with the West Spitsbergen Current was diverted to the east of Svalbard and then into the Arctic Basin. This produced an approximate balance between inflow and outflow. Undoubtedly, part of the reason for this is inadequate topographic resolution. However, there may also be difficulties due to inadequate vertical resolution, yielding too deep a shelf in the Barents Sea. These issues will be addressed in future work. 


\section{ACKNOWLEDGEMENTS}

This work was supported by the Office of Naval Research under contract N00014-8OR6-K-069.

\section{REFERENCES}

Aagaard, K. and E.C. Carmack. 1989. The role of sea ice and other fresh water in the Arctic circulation. $\mathcal{F}$. Geophys. Res., 94(C10), 14,485-14,498.

Bryan, K. 1969. A numerical method for the study of the circulation of the world oceans. F. Comput. Phys., 4, 347376.

Hibler, W.D., III. 1979. A dynamic thermodynamic sea ice model. 7. Phys. Oceanogr., 9(4), 815-846.

Hibler, W.D., III, and K. Bryan. 1987. A diagnostic iceocean model. F. Phys. Oceanogr., 17(7), 987-1015.

Hibler, W.D., III, and P. Ranelli. 1990. Seasonal and interannual simulations with a large scale ice-ocean model. In Johannessen, J.A., P.M. Haugan, and W.B.
Owens, eds. Regional and mesoscale modeling of ice covered oceans, Solstrand Fjord Hotel, ... Os, Norway, 23-27 October 1989. Workshop proceedings. Bergen, Nansen Remote Sensing Center, 205-209.

Ip, C. F., W.D. Hibler, III, and G.M. Flato. 1991. On the effect of rheology on seasonal sea-ice simulations. Ann. Glaciol., 15, 17-25.

Levitus, S. 1982. Climatological atlas of the world ocean. NOAA Prof. Pap. 13.

Parkinson, C.L. and W.M. Washington. 1979. A largescale numerical model of sea ice. 7. Geophys. Res., 84(Cl), 311-337.

Ries, J.E. and W.D. Hibler, III. 1991. Interannual characteristics of an $80 \mathrm{~km}$ resolution diagnostic Arctic ice-ocean model. Ann. Glaciol., 15, 155-162.

Semtner, A.J., Jr. 1987. A numerical study of sea ice and ocean circulation in the Arctic. 7. Phys. Oceanogr., 17(8), 1077-1099.

The accuracy of references in the text and in this list is the responsibility of the authors, to whom queries should be addressed. 